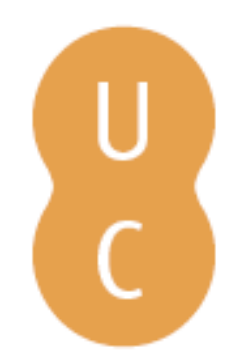

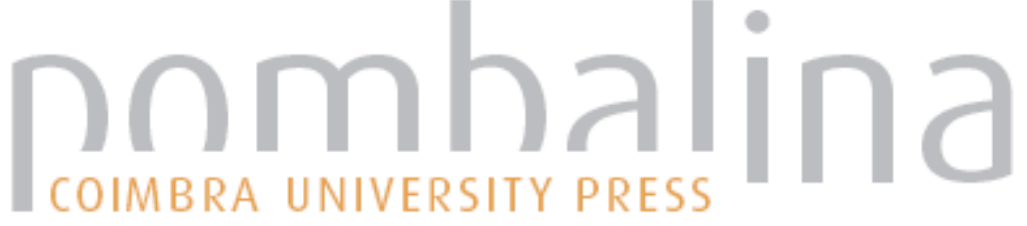

\section{A GEPS e a Universidade de Coimbra}

\author{
Autor(es): $\quad$ Russo, Jorge
}

Publicado por: Imprensa da Universidade de Coimbra

URL

persistente: URI:http://hdl.handle.net/10316.2/38361

DOI: $\quad$ DOI:http://dx.doi.org/10.14195/978-989-26-0438-1_22

Accessed : $\quad$ 26-Apr-2023 11:58:37

A navegação consulta e descarregamento dos títulos inseridos nas Bibliotecas Digitais UC Digitalis, UC Pombalina e UC Impactum, pressupõem a aceitação plena e sem reservas dos Termos e Condições de Uso destas Bibliotecas Digitais, disponíveis em https://digitalis.uc.pt/pt-pt/termos.

Conforme exposto nos referidos Termos e Condições de Uso, o descarregamento de títulos de acesso restrito requer uma licença válida de autorização devendo o utilizador aceder ao(s) documento(s) a partir de um endereço de IP da instituição detentora da supramencionada licença.

Ao utilizador é apenas permitido o descarregamento para uso pessoal, pelo que o emprego do(s) título(s) descarregado(s) para outro fim, designadamente comercial, carece de autorização do respetivo autor ou editor da obra.

Na medida em que todas as obras da UC Digitalis se encontram protegidas pelo Código do Direito de Autor e Direitos Conexos e demais legislação aplicável, toda a cópia, parcial ou total, deste documento, nos casos em que é legalmente admitida, deverá conter ou fazer-se acompanhar por este aviso.

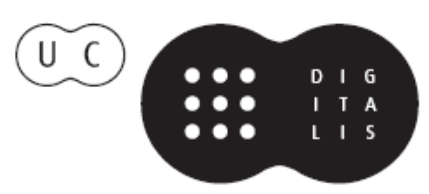


Francisco de Oliveira

Pascal Thiercy

Raquel Vilaça

Coordenação

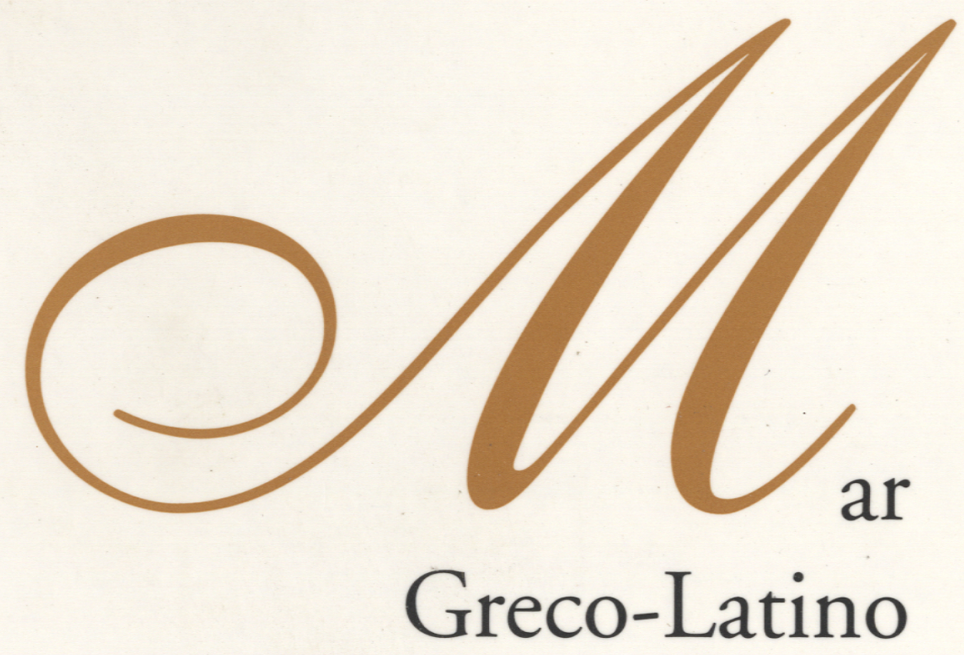

- colmbra 2006 
A GEPS E A UNIVERSIDADE DE COIMBRA

Jorge Russo

Presidente do GEPS

\section{Introdução}

O GEPS - Grupo de Estudos e Pesquisas Subaquáticas, associação sem fins lucrativos que se dedica ao estudo e salvaguarda do património arqueológico náutico e subaquático, foi fundado em Peniche no mês de Março de 2004, onde está sediada.

Como fundadores, o GEPS teve um grupo de mergulhadores, todos apaixonados pela história e arqueologia, incentivados pelo arqueólogo Filipe Castro da Universidade A\&M do Texas - EUA, cujo contributo para a salvaguarda do património arqueológico subaquático local era o seu comum interesse.

Porque arqueologia não se faz apenas com um grupo de amigos mergulhadores, desde cedo o GEPS procurou as competências que permitissem desenvolver as suas actividades de forma cientifica e tecnicamente correcta.

Ainda em 2004, o GEPS firmou protocolos de colaboração com a Universidade de Coimbra e com o Instituto Português de Arqueologia através do seu Centro Nacional de Actividades Náuticas e Subaquáticas (CNANS), a que se seguiram as Câmaras Municipais da Lourinhã e de Peniche.

O Facto de a Direç̧ão Científica do GEPS ser assegurada pelo Exmo. Professor Doutor Vasco Gil Mantas, muito tem contribuído para o sucesso dos resultados, bem como para a facilitação das relações institucionais com a 
Universidade de Coimbra e o desenvolvimento do Protocolo de Colaboração firmado.

Presentemente, os associados do GEPS provêm de valências tão distintas como a Arqueologia, História, Arquitectura, Engenharia, Direito, Design, Informática, Medicina e a Gestão de Empresas, incluindo alunos de história e Arqueologia, maioritariamente da Universidade de Coimbra.

Hoje, apesar de o GEPS se constituir como uma muito pequena Associação, com um orçamento anual tão ridículo que não ultrapassa os $3.000 €$, totalmente provenientes de quotizações, desenvolve e/ou está envolvido em três projectos arqueológicos subaquáticos distintos, em articulação com o CNANS no âmbito do Programa de Inventário Nacional do Património Subaquático, em três localizações diferentes; em dois projectos de investigação de arquivo e um projecto ligado ao método construtivo de uma embarcação de pesca tradicional, todos eles desenvolvidos em dois concelhos: Peniche e Lourinhã.

\section{Os Projectos}

\subsection{Peniche}

\subsubsection{Naufrágio do Período Romano dos Cortiçais}

Descle 2004 que o Arqueólogo Jean-Yves Blot se encontra a dirigir, como assessor do CNANS, um projecto arqueológico subaquático do IPA/CNANS no sítio dos Corticais, na costa Sul de Peniche.

Mais uma vez, este importante sítio arqueológico foi achado por um caçador submarino, Luís Santos Jorge, quando no início de 2004 fazia a sua habitual apneia naquela zona.

Este caçador submarino viria a deparar-se com materiais cerâmicos que não conseguiu identificar, mas que um seu amigo lhe disse serem ânforas. Mais tarde, o mergulhador e médico de Peniche, Luís Fonseca, ao saber deste 
achado, contactava com Jean-Yves Blot que, com o GEPS, faria no final de 2004 as primeiras imersões de investigação do sítio.

Este achado fortuito, foi de imediato declarado pelo Luís Santos Jorge, numa atitude que deveria ser tomada como modelo, pois não só deu cumprimento ao conjunto normativo que enquadra legalmente estes achados como deu a conhecer este importante sítio arqueológico subaquático.

Em 2005 realizaram-se mais duas campanhas arqueológicas, com o apoio da Câmara Municipal de Peniche, que garantiu o alojamento e as refeições de toda a equipa, e que permitiram que António Dias Diogo caracterizasse os mais de 2000 fragmentos de cerâmica identificados como ânforas Haltern 70 (Figura 1 e 2), com proveniência Bética, que transportariam produtos vinários, e como sigillata itálica (Figura 3), datável de entre 15 a.c e 15 d.c.

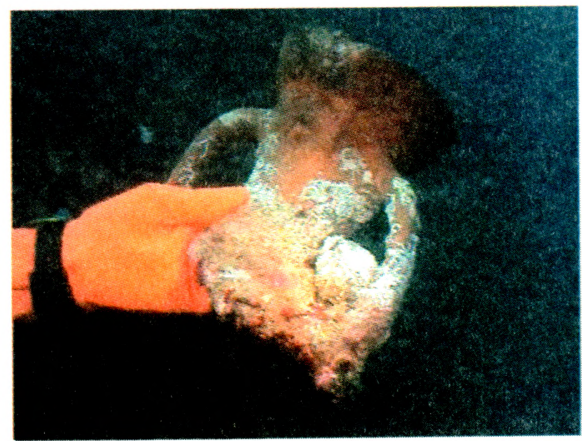

Figura 1 - Fragmento de Haltern 70 - Foto: Carlos Antunes

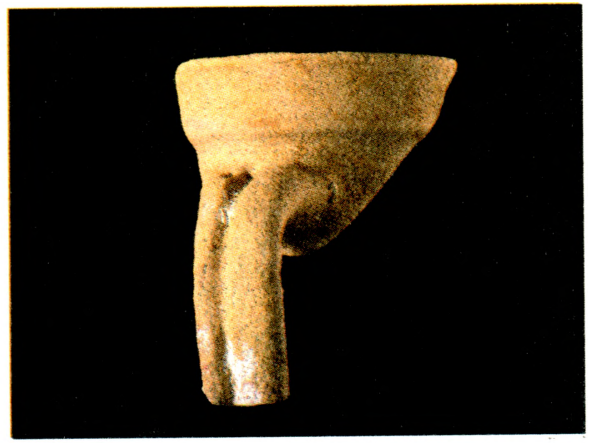

Figura 2 - Fragmento de Haltern 70 - Foto: Jorge Russo

Este sítio, em conjunto com os resultados dos trabalhos levados a cabo no fundeadouro da Berlenga, nos fornos romanos do Murraçal da Ajuda (Penichei)" e em terra na própria Berlenga, viriam a mudar o panorama que se aceitava para a ocupação romana da então ilha de Peniche e de todo o litoral Atlântico peninsular da

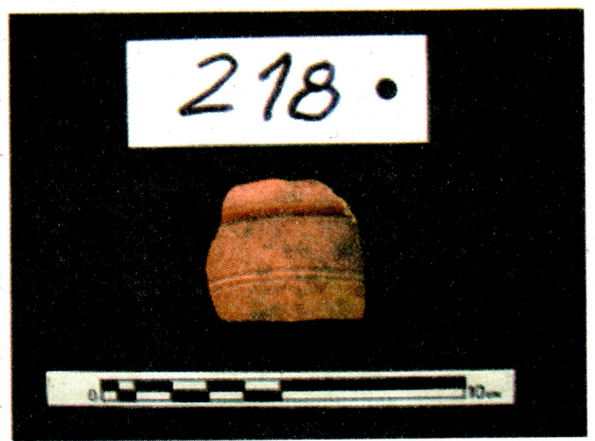

Figura 3 - Fragmento de Sigilata Itálica - Foto: Jorge Russo 
antiguidade, não esquecendo a importância desta visão para as problemáticas ligadas com a "Rota Atlântica no período romano na transição da era".

Em todas estas campanhas, a maioria da equipa que o GEPS disponibilizou para este sítio foi constituída por alunos, recém licenciados e candidatos a doutoramento provenientes da Universidade de Coimbra, ao abrigo do Protocolo de Colaboração firmado.

\subsubsection{A Traineira de Peniche - Registo do seu método construtivo}

Com a construção da última Traineira em Peniche e o encerramento do estaleiro da Gamboa, o GEPS iniciou o estudo e o registo do método construtivo e arqueologia naval da Traineira de Peniche, embarcação tradicional de pesca da sardinha pelo método do cerco.

Este registo, que se realizará com um conjunto de entrevistas ao Mestre deste estaleiro, Sr. José Maria Cativo, ou seja, o método construtivo e a arquitectura da Traineira de Peniche contados na primeira pessoa, será acompanhado pelo registo fotográfico exaustivo da construção de um modelo à escala 1:20 (Figura 4), que se encontra a ser realizado por um carpinteiro daquele estaleiro, o agora modelista, Sr. Fernando Malheiros (Figura 5).

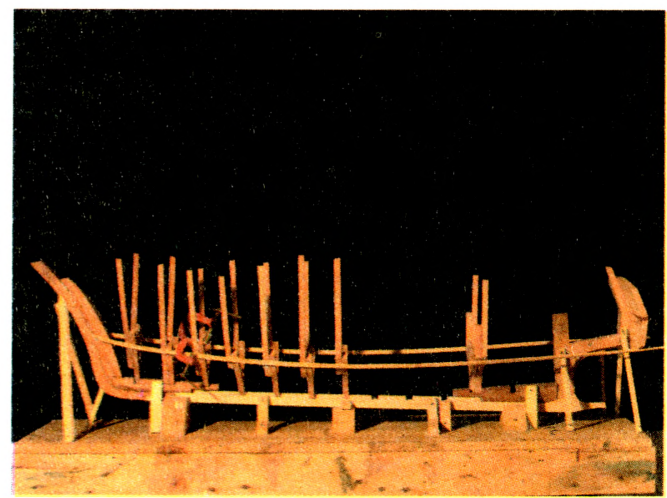

Figura 4 - Construção de uma traineira de Peniche à escala 1:20 - Foto: Jorge Russo

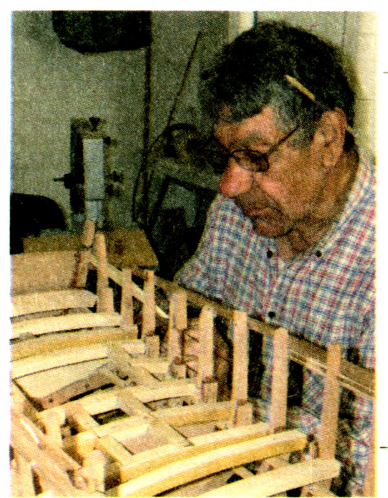

Figura 5 - Sr. Fernando Malheiros, modelista e antigo carpinteiro naval - Foto: Jorge Russo 
Este trabalho, que terá a forma de um livro, pretende perpetuar uma arte tradicional cujas origens se perdem no tempo e que corre o risco de se perder nas nossas memórias.

\subsubsection{Carta Arqueológica Subaquática do Concelho de Peniche}

Os projectos que nos encontramos a desenvolver ou com os quais colaboramos, integram-se num programa mais vasto com vista à Carta Arqueológica Subaquática do Concelho da Peniche.

Neste trabalho de registo e investigação sistemática, não esqueceremos o nosso passado mais recente e os numerosos naufrágios ocorridos neste Concelho nos séculos XIX e XX, dos quais o cemitério da Bailadeira, nos Farilhões, é um exemplo de características ímpares em Portugal, pela concentração de navios e pelas condições excelentes que possui para um destino de mergulho turístico que permita uma maior consciencialização da necessidade da protecção destes testemunhos, ao invés da sua delapidação.

Em 2005, realizar-se-ão duas quinzenas de investigação do arquivo documental municipal, uma em Abril e outra em Setembro/Outubro, com coordenação presencial do arqueólogo Municipal Rui Venâncio e o envolvimento de 8 alunos da Universidade de Coimbra (Figura 6).

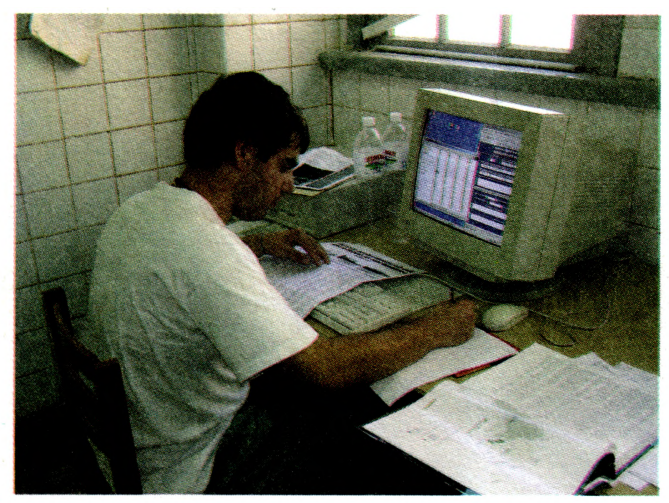

Figura 6 - Vítor Frazão, aluno de arqueologia da Universidade de Coimbra, na investigação do arquivo do museu de Peniche - Foto: Jorge Russo 


\section{$\underline{2.2 \text { Lourinhã }}$}

2.2.1 Naufrágio do Século XVII ou XVIII de Vale de Frades

Desde a sua fundação em 2004 que o GEPS se encontra a desenvolver o estudo arqueológico do naufrágio de um navio, presumivelmente do século XVII ou XVIII, cujos vestígios tinham sido declarados em 1973 por dois mergulhadores amadores locais - José Filipe Martins e José Veríssimo.

Este achado seria alvo de uma primeira investigação em 1986, num mergulho realizado por Francisco Alves (Actual Director do CNANS), pelo Arqueoólogo Jean-Yves Blot, que na altura desenvolvia em Peniche trabalhos arqueológicos subaquáticos no galeão espanhol setecentista San Pedro de Alcântara, e pelo Arqueólogo Mário Almeida.

Do achado, do mergulho de 1986 e do trabalho até aqui desenvolvido pelo GEPS no sítio de Vale de Frades, foi possível identificar um conjunto de 4 canhões de ferro (Figura 7), uma âncora de ferro, escumilha, balas de mosquete e cordões de chumbo (Figura 8), assim como diversos fragmentos de faiança, presumivelmente provenientes de produções de Coimbra e do século XVII ou XVIII.

Nas campanhas levadas a cabo pelo GEPS em Vale de Frades, estiveram mais numa vez envolvidos alunos da Universidade de Coimbra.

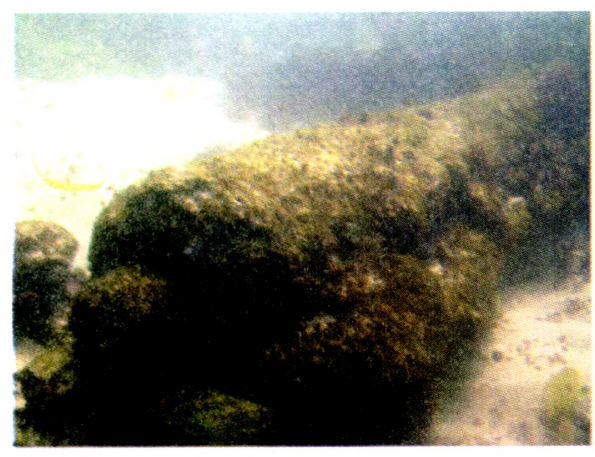

Figura 7 - Canhão de ferro em Vale de Frades na Lourinhã - Foto: Jorge Russo

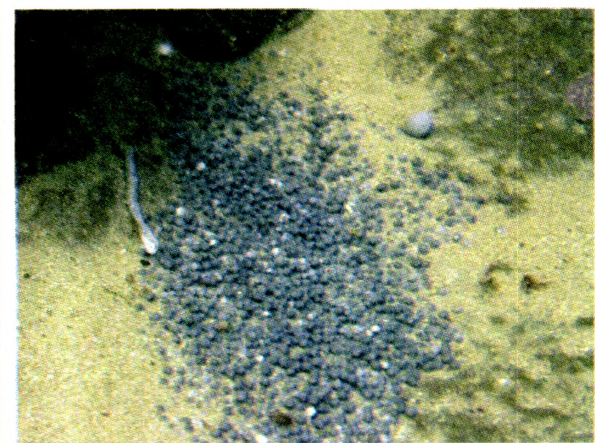

Figura 8 - Escumilha, bala de mosquete e cordão de chumbo em Vale de Frades na Lourinhã Foto: Jorge Russo 


\subsubsection{Naufrágio do Galeão Seiscentista São Nicolau}

Em 2005, iniciámos o estudo histórico e historiográfico do naufrágio do galeão seiscentista S. Nicolau, que naufragou em 1642 na costa deste Concelho.

Este galeão, navio almirante da esquadra constituída por navios de Portugal, França e Holanda, rumava à Terceira a fim de a libertar do domínio Espanhol que ainda se fazia sentir. Viria a perder-se junto à Ponta do Peralta Porto das Barcas, no decurso de uma violenta tempestade.

O estudo deste importante achado, constitui-se, achamos, de grande relevância, pois teve um enorme impacto local (vejam-se as armas da freguesia da Atalaia, que ostentam este naufrágio), e contribuirá, para o estudo do enquadramento político da época.

Com o auxílio do achador de uma meia colubrina de bronze, hoje patente no Museu da Marinha em Lisboa, descoberta na área provável do naufrágio do São Nicolau, o GEPS desenvolverá missões no terreno, a fim de localizar materiais e iniciar o seu estudo arqueológico.

\subsubsection{Carta Arqueológica Subaquática do Concelho da Lourinhã}

Os anteriores projectos inserem-se num programa de actividades mais vasto com vista à Carta Arqueológica Subaquática do Concelho da Lourinhã, à semelhança do projectado para Peniche.

Em 2005, 2 alunos da Universidade de Coimbra e 2 alunas da Universidade de Lisboa, e em 2006 um aluno da Universidade de Coimbra, estiveram envolvidos na investigação historiográfica do fundo documental municipal, contribuindo inclusivamente para a sua organização, inventariação e medidas de higienização (Figura 10), com o apoio da Câmara Municipal da Lourinhã, que assegurou o alojamento e refeições da equipa do GEPS. 


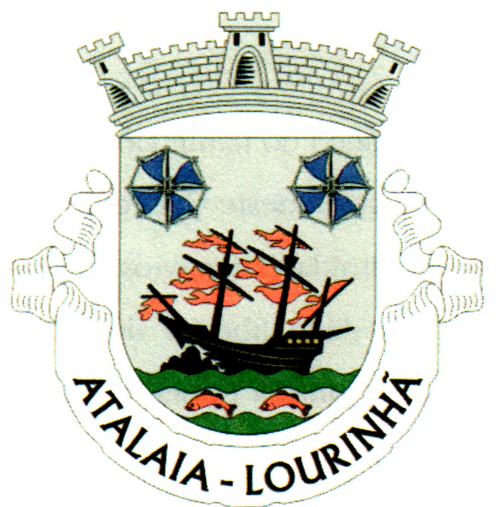

Figura 9 - Brasão da Freguesia da Atalaia, Concelho da Lourinhã

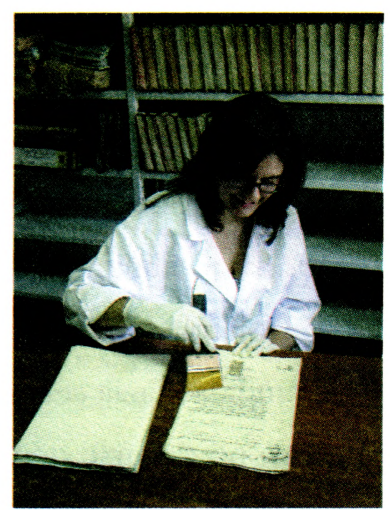

Figura 10 - Sónia Bombico, associada do GEPS e recém licenciada em Arqueologia pela Universidade de Coimbra, na investigação documental do Arquivo da Municipal da Lourinhã Foto Jorge Russo

\section{Conclusão}

Ao contrário do que seria de esperar, em Portugal, mais uma Associação sem fins lucrativos não significou mais um grupo de amigos que legalmente deram forma ao seu hobby.

O Protocolo que o GEPS firmou com a Universidade de Coimbra, ao contrário de muitos outros protocolos firmados em Portugal, também não significou uma forma legal de financiamento de actividades colegiais, nem um passo para a redacção de várias linhas de relatórios ou planos de actividades.

A forma como a Universidade de Coimbra tem dado o seu apoio aos projectos do GEPS e a forma como o GEPS tem enquadrado alunos daquela Universidade, deram forma eficiente, produtiva e relevante àquilo que podem ser todos os protocolos de colaboração entre Universidades e instituições externas às mesmas.

$\mathrm{Na}$ realidade, em pouco mais de um ano, o GEPS desenvolveu todos os projectos que referimos e que resumidamente caracterizámos, e a Universi- 
dade de Coimbra conseguiu, desta forma, enquadrar várias dezenas dos seus alunos em projectos reais, onde estes tiveram reais competências e responsabilidades, estando o GEPS em crer que todos eles usufruíram de experiências que muito relevantemente se materializarão na sua qualificação como profissionais e cientistas em moldes que todos pretendemos para todos os alunos num futuro muito próximo.

Estes e outros argumentos servem-nos de motivação para o desenvolvimento de mais e melhores projectos, acreditando que, com a colaboração dos nossos associados, presentes e futuros, de instituições como aquelas com que protocolamos cooperações e de outras com quem pretendemos vir a colaborar, seremos capazes de nos superar mais e mais. O objectivo último não se perde de vista: o estudo do património arqueológico subaquático e a sua salvaguarda, através, inclusivamente, da criação de medidas com vista à consciencialização da comunidade de mergulhadores amadores e das populações locais.

\section{Agradecimentos}

O GEPS gostaria de agradecer a confiança dada pelo IPA/CNANS ao protocolar colaborações com o GEPS, à Universidade de Coimbra por todo o apoio que tem prestado ao desenvolvimento dos nossos projectos, nomeadamente ao nosso Director Científico Exmo. Professor Doutor Vasco Gil Mantas, pela qualidade e empenhamento do seu apoio e pela forma como tem materializado o cumprimento e implementação do Protocolo que firmámos com a Universidade de Coimbra, às Câmaras Municipais de Peniche e Lourinhã pela colaboração prestada, que se revelou determinante para o desenvolvimento dos nossos projectos, e em último lugar, mas de forma sublinhada, a todos os alunos da Universidade de Coimbra que, usufruindo de experiência pedagógica, souberam dar um contributo muito significativo para o desenvolvimento 
dos projectos referidos. Nomes como Sónia Bombico (Licenciada em Arqueologia); Vítor Frazão (Aluno de Arqueologia); Óscar Nogueira (Aluno de Arqueologia e Psiquiatra), Alessia Amato (Italiana candidata a doutoramento em Arqueologia); Emanuele (Italiano, Aluno de Arqueologia) e Sónia Silva Simões (Aluna de Arqueologia) todos provenientes da Universidade de Coimbra e alguns deles associados do GEPS, merecem especial referência. 